\title{
Application of wind profiler data to rainfall analyses in Tazhong Oilfield region, Xinjiang, China
}

\author{
MinZhong WANG ${ }^{1,2}$, WenShou WEI ${ }^{1,2 *}$, Qing HE ${ }^{1,2}$, XinChun $\mathrm{LIU}^{1,2}$, ZhongJie ZHAO \\ ${ }^{1}$ Urumqi Institute of Desert Meteorology, China Meteorological Administration, Urumqi 830002, China; \\ ${ }^{2}$ Taklimakan Desert Atmospheric Environment Observation Experimental Station, Tazhong 841000, China; \\ ${ }^{3}$ Meteorological Office of Bayinguoleng Mongolian prefecture, Kurler 841000, China
}

\begin{abstract}
To improve the level of meteorological service for the Oilfield region in the Taklimakan Desert, the Urumqi Institute of Desert Meteorology of the China Meteorological Administration (CMA) conducted a detection experiment by means of wind profiling radar (WPR) in Tazhong Oilfield region of Xinjiang, China in July 2010. By using the wind profiler data obtained during the rainfall process on 27 July, this paper analyzed the wind field features and some related scientific issues of this weather event. The results indicated that: (1) wind profiler data had high temporal resolution and vertical spatial resolution, and could be used to analyze detailed vertical structures of rainfall processes and the characteristics of meso-scale systems. Before and after the rain event on 27 July, the wind field showed multi-layer vertical structures, having an obvious meso-scale wind shear line and three airflows from different directions, speeding up the motion of updraft convergence in the lower atmosphere. Besides, the wind directions before and after the rainfall changed inversely with increasing height. Before the rain, the winds blew clockwise, but after the onset of the rain, the wind directions became counterclockwise mainly; (2) the temperature advection derived from wind profiler data can reproduce the characteristics of low-level thermodynamic evolution in the process of rainfall, which is capable to reflect the variation trend of hydrostatic stability in the atmosphere. In the early stage of the precipitation on 27 July, the lower atmosphere was mainly affected by warm advection which had accumulated unstable energy for the rainfall event and was beneficial for the occurrence of updraft motion and precipitation; (3) the "large-value zone" of the radar reflectivity factor $Z$ was virtually consistent with the onset and end of the rainfall, the height for the formation of rain cloud particles, and precipitation intensity. The reflectivity factor $Z$ during this event varied approximately in the range of 18-38 dBZ and the rain droplets formed mainly at the layer of $3,800-4,500 \mathrm{~m}$.
\end{abstract}

Keywords: wind profiling radar; vertical atmospheric structure; temperature advection; radar reflectivity factor Z; Tazhong Oilfield; Taklimakan Desert

Tarim Oilfield is the second largest oilfield in Chinese Mainland. It is located in the Taklimakan Desert, Xinjiang, with rich oil and gas reserves. By 2011, 26 oil and gas fields had been discovered in Tarim Oilfield, forming 4 oilfield groups including Tazhong Oilfield, Donghe Oilfield, Lunnan Oilfield, and Hade Oilfield. Tarim Oilfield has been playing a more and more important role in the energy structure of China, so it is named by economists as an energy economical pillar over western China.

Tazhong Oilfield is the largest desert oilfield that has been explored and developed in the Tarim Oilfield region. After the construction of more than 10 years, it has developed into an oilfield of considerable scale. Now there are about 1,000 workers in the oilfield. The annual output of the oilfield is over one million tons and, so far, it has produced $16.69 \times 10^{6}$ tons of crude oil and $4.097 \times 10^{9} \mathrm{~m}^{3}$ of natural gas in total, making great contribution to the exploitation and utilization of gas and oil resources in China. However, the natural conditions in Tazhong Oilfield are very poor with an extremely dry climate. Frequent weather disasters bring

Received 2012-02-15; accepted 2012-08-01

"Corresponding author: WenShou WEI (E-mail: Weiwsh@idm.cn) 
a great many difficulties to the oilfield exploration and development as well as the workers' daily lives. Due to the lack of a sounding site and Doppler weather radar in the desert area, the atmospheric dynamics and mechanisms for different abnormal weather processes have not been explained scientifically and profoundly yet, so that there is no way to make very accurate and detailed weather forecasts.

Wind profiling radar (WPR) is an upper-air remote sensing system first developed in the 1960s (He et al., 2010). It can monitor and detect various weather events in a convenient and real-time manner, and can depict the detailed structures of atmospheric motion, and moreover it can retrieve the distribution of temperature advection with time and height by adopting high-resolution wind profiler data (Zhang et al., 2007). Scientists have used wind profilers to address a wide range of scientific issues including wind field detection (Balsley et al., 1988; Angevine, 1997; Zou et al., 2007; Xin et al., 2009), numerical weather predictions (Kuo et al., 1987), precipitation processes (Fukao et al., 1985; Chilson et al., 1993; Ecklund et al., 1995; Gage et al., 1996; Rao et al., 1999; Deshpande and Raj, 2009), and rain droplet spectrum retrieval (Wakasugi et al., 1986; Currier et al., 1992; Maguire and Avery, 1994). Ruan et al. (2002) analyzed the vertical structure and evolution features of rain clouds by utilizing the return signal power of WPR. Gu et al. (1993) studied local rainstorms and frontal weather processes by using wind profiler data in Beijing, showing the applicability of his approach to short-time forecasts. He et al. (2009) analyzed the characteristics of wind profiles during the rainfall processes in Yanqing county, Beijing, suggesting that the data could express large-scale airflow fields in a timely manner and be applied to precipitation forecasts. In this study, the Urumqi Institute of Desert Meteorology of the China Meteorological Administration (CMA) conducted a detection experiment in Tazhong Oilfield of the Taklimakan Desert in July 2010, and used the wind profiler data observed during the rainfall process on 27 July to analyze the characteristics of the wind field in this weather event, and furthermore, to elaborate the strong points and values of wind profiles in weather analysis. It is envisaged through this study that high temporal resolution wind profiler data can be applied to weather analyses and forecasts for the Tarim Oilfield region so that more accurate and fine meteorological services can be offered for the exploration and development of the oilfield.

\section{Study area and methods}

The Tazhong Oilfield $\left(39^{\circ} 00^{\prime} \mathrm{N}, 83^{\circ} 40^{\prime} \mathrm{E} ; 1,099.3 \mathrm{~m}\right.$ asl) is located in the hinterland of the Taklimakan Desert, which is the largest shifting desert in China. The mean annual precipitation is less than $40 \mathrm{~mm}$ and sand/dust storms are very frequent. The study area is open all around. The ground surface is covered by sand dunes.

The equipment used for this study is a CFL-03 phased-array wind profiler (Fig. 1, hereinafter referred to as CFL-03; China Aerospace Science and Industry Corporation, Beijing, China), mainly consisting of six units: transmitter, receiver, antenna feeder, monitoring system, signal processing, and control and data processing package. As its designed detection height is $3,000-5,000 \mathrm{~m}$, it is a boundary layer wind profiler. The CFL-03 transmits fine beams in fixed directions, one vertical beam and four tilt beams $15^{\circ}$ apart. These tilt beams are evenly and orthogonally distributed across azimuth. To ensure a proper balance between desired detection heights and higher resolutions at lower levels, the CFL-03 operates in high and low resolution modes alternately. The low mode applies narrow pulse and its height resolution is $50 \mathrm{~m}$, while the high mode uses broad pulse with a height resolution of $100 \mathrm{~m}$. The two modes work in turn, ensuring the higher detection altitudes and higher resolution at lower levels at the same time. The data format offered by CFL-03 fully meets the CMA criteria for spectrum data, radial spectrum velocity, and real-time profile in both modes. Each profile contains horizontal wind, vertical velocity, signal-to-noise ratio (SNR), turbulence refractive index structure constant $\left(C_{n}^{2}\right)$, and spectral width. Table 1 lists the major technical parameters of the CFL-03 wind profiler.

The datasets used in this paper include the observations (temporal resolution: $12 \mathrm{~min}$; height resolution: 50 or $100 \mathrm{~m}$ ) of horizontal speed, wind direction and SNR which were obtained by the CFL- 03 wind profiler in the Tazhong Oilfield in 27-28 July 2010 and 
Table 1 Technical parameters of the CFL-03 wind profiler

\begin{tabular}{lllcc}
\hline Item & Parameter & Item & High mode parameter & Low mode parameter \\
\hline Radar wavelength & $227 \mathrm{~mm}$ & Pulse width & $0.66 \mu \mathrm{s}$ & $0.33 \mu \mathrm{s}$ \\
Beam width & $8^{\circ}$ & Minimum detection altitude & $600 \mathrm{~m}$ & $50 \mathrm{~m}$ \\
Beam number & 5 & Noise coefficient & $2 \mathrm{~dB}$ & $2 \mathrm{~dB}$ \\
Antenna gain & $25 \mathrm{~dB}$ & Height resolution & $100 \mathrm{~m}$ & $50 \mathrm{~m}$ \\
Feeder loss & $2 \mathrm{~dB}$ & Coherent accumulation number & 64 & 100 \\
Receiver & Digital IF & FFT points & 512 & 256 \\
Transmitting peak power & $2.36 \mathrm{KW}$ & Bandwidth & $1.5 \mathrm{MHz}$ & $3.0 \mathrm{MHz}$ \\
\hline
\end{tabular}

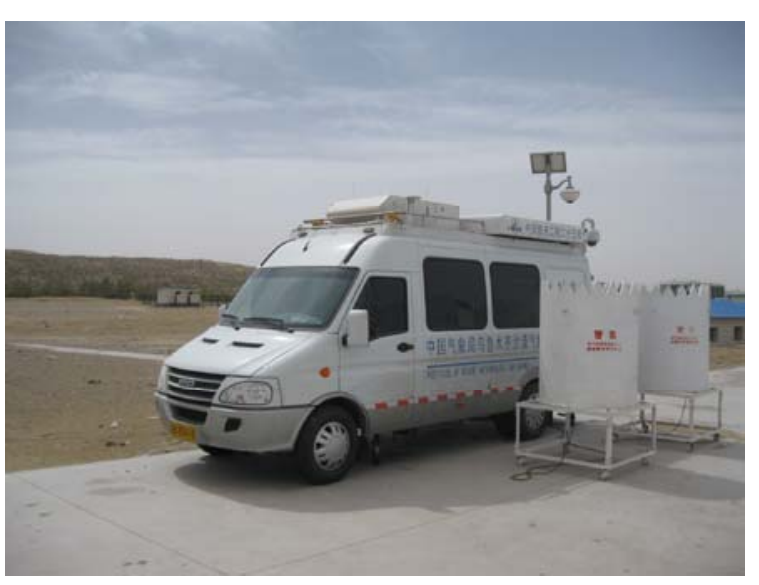

Fig. 1 Mobile CFL-03 wind profiler operated in Tazhong Oilfield

the NCEP reanalysis with spatial resolution $1^{\circ} \times 1^{\circ}$. The wind profiler is at Tazhong Weather Station that is located in the oilfield, where the observation field is open all around and thus not influenced by big ground echoes.

\section{Results and discussion}

\subsection{Brief description and analysis of rainfall processes}

Being affected by the eastward motion of West Siberian trough, the Tazhong Oilfield region received a rainfall process on 27 July 2010 . The rain was mainly concentrated in the periods of 07:33-08:48, 09:56-10:33, 12:11-12:40, 14:08-14:27, 15:12-15:25, 15:45-16:13, 16:39-17:09, 18:04-20:05, 20:40-20:57, 21:16-22:27 and 22:46-22:55, generating a total precipitation amount of $2.5 \mathrm{~mm}$.

The South Asian High, with dual centers, appeared at the $100 \mathrm{hPa}$ level in late July, with West Siberian being controlled by a long-wave trough. Before it rained, a strong southwesterly jet was sustained in the front of the Siberian trough at $200 \mathrm{hPa}$, with its maximum wind speed reaching $56 \mathrm{~m} / \mathrm{s}$. The southwesterly jet brought about abundant moisture, strengthening the divergence in the upper atmosphere and creating a favorable condition for the updraft convergence in the lower atmosphere.

The $500 \mathrm{hPa}$ chart on 26 July (data not shown) presented that Xinjiang was dominated by the subtropical high over the West Pacific, protruding west and blocking from the north. Meanwhile, the subtropical high over Iran was developing further north and gradually overlapped with the Ural High, intensifying the meridional circulation over the Eurasian continent, and the West Siberian trough deepened southward, joining the southern subtropical trough. On 27 July (Fig. 2) the Ural ridge was invaded by an unstable small trough, pushing the downstream subtropical trough eastward and influence Xinjiang, and leading to the rainfall process in the Taklimakan Desert region. As can be seen from the surface chart, before the deep subtropical trough got near to Xinjiang, the southern basin of Xinjiang was controlled by a strong and warm low pressure with a central pressure value of 992.5 $\mathrm{hPa}$. Correspondingly, the surface high pressure reached $1,025 \mathrm{hPa}$, establishing burst gradients, and

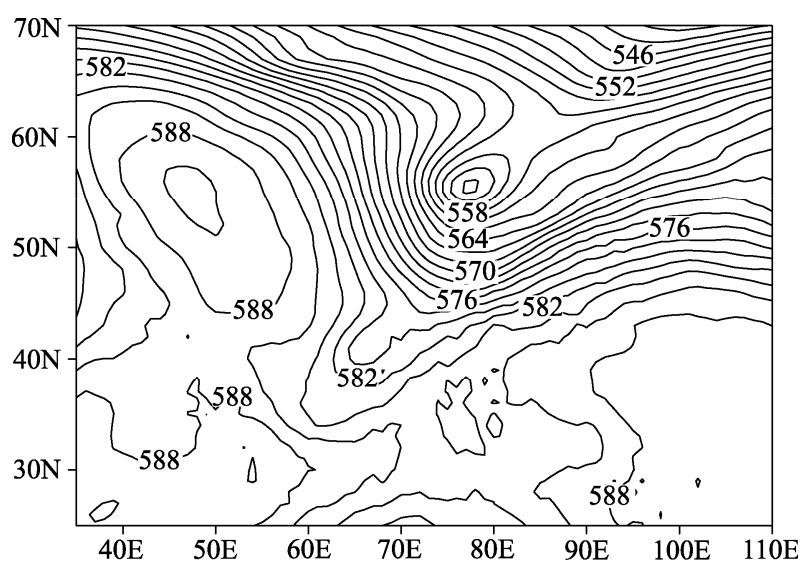

Fig. 2 The $500 \mathrm{hPa}$ height fields at 08:00, 27 July 2010 
thus providing a favorable condition for the occurrence of the rainfall event.

\subsection{Applications of wind profiles}

2.2.1 Horizontal wind fields

Due to the high temporal resolution and good vertical spatial resolution of wind profiler data, fine structures and meso-scale system features of the continuous evolution of wind fields in the atmosphere during the rainfall process can be investigated in detail through analysis of wind directions and speeds in the vertical direction.

Figure 3 shows the horizontal wind speed with time and height in the process of the rainfall over Tazhong Oilfield on 27 July 2010. Before the precipitation, the wind fields can be divided into three stages. At the first stage (00:00-02:30), two vertical wind layers existed in the atmosphere: northwesterly airflow in the bottom layer below $700 \mathrm{~m}$ and easterly airflow in the layer above $800 \mathrm{~m}$, and their directions changed with height clockwise. At the second stage (02:30-04:40), four vertical wind layers were found in the atmosphere: in the low layer under $700 \mathrm{~m}$ the northerly airflow and westerly airflow prevailed; in the layer of 700-1,500 m easterly wind blew and of 1,500-3,400 m southerly wind blew; and finally, above 3,500 m northerly wind dominated. At the third stage (04:40-06:30), the airflows changed into southwesterly, westerly and northwesterly winds clockwise upwards in turn from the easterly wind in the bottom layer. The analyses suggest that multi-layer structures played the main role in the wind fields vertically before the rain and in the high level below $3,500 \mathrm{~m}$, and the airflows changed their directions clockwise with the variation of height. According to the thermal wind principle, the atmosphere in this layer was impacted by the warm advection, which accumulated unstable energy for the coming rains, acting as the dynamic conditions for the upward motion of airflows and convergence of water vapors.

After the rainfall on 27 July (Figs. 3b-g), the multi-layer structures still existed in the atmosphere and gradually developed into one evident meso-scale wind shear line at the high level of 4,000 m. Above the shear line the airflows presented as southeasterly, southerly and southwesterly winds in turn, while at the level of 1,000-4,000 $\mathrm{m}$ under the shear line the wind fields could be divided into three stages roughly. At the first stage (07:30-16:00 on 27 July) easterly airflows flew at the layer of 1,000-2,500 $\mathrm{m}$ and northerlies at the layer of 2,500-4,000 m. The winds turned counterclockwise, going with heights. At the second stage (16:00-20:20 on 27 July), the northwesterly airflows at the layer of 1,000-2,000 m changed clockwise into northerly winds and easterly winds with time and height. At the third stage, after 20:20 on 27 July, the easterly winds at the bottom layer of the atmosphere developed counterclockwise again into northeasterly and northerly winds in turn with the changes of height (no rain on 28 July, and so no more description here). From the continuous variations of the horizontal wind fields, it is seen that during the precipitation, three airflows from different directions existed in the sky over Tazhong Oilfield. Southerly winds were above the level of $4,000 \mathrm{~m}$ (corresponding to the height of $500 \mathrm{hPa}$ approximately), northerly and northeasterly winds at the layer of 3,000-4,000 $\mathrm{m}$ and easterly airflows at the layer of 1,000-2,500 m (matching the heights of $850-700 \mathrm{hPa}$ roughly). The three airflows accelerated the updraft convergence of the atmosphere at lower levels, providing a favorable factor for the arrival of precipitation.

As shown in the above analyses, although the wind profiling radar only provides data of vertical wind speeds and directions on a local scale, the data have very high resolutions, not only in temporal scales but also in vertical spatial scales, and can be used to analyze detailed vertical structures of a rainfall process and some characteristics of a meso-scale system (e.g. meso-scale shear line). Before and after the precipitation on 27 July, the wind fields showed multi-layer structures vertically with three airflows, i.e. the southerly, northerly, and easterly winds, speeding up the motion of updraft convergence in the lower atmosphere. The wind directions before and after the rainfall varied inversely with the changes of height. Before the onset of the rain, wind directions turned clockwise with height and the lower atmosphere was dominated by warm advection which had accumulated unstable energy for the rainfall weather; after it began to rain, wind directions changed counterclockwise and the atmosphere below 3,000 m was mainly affected by cold advection. 

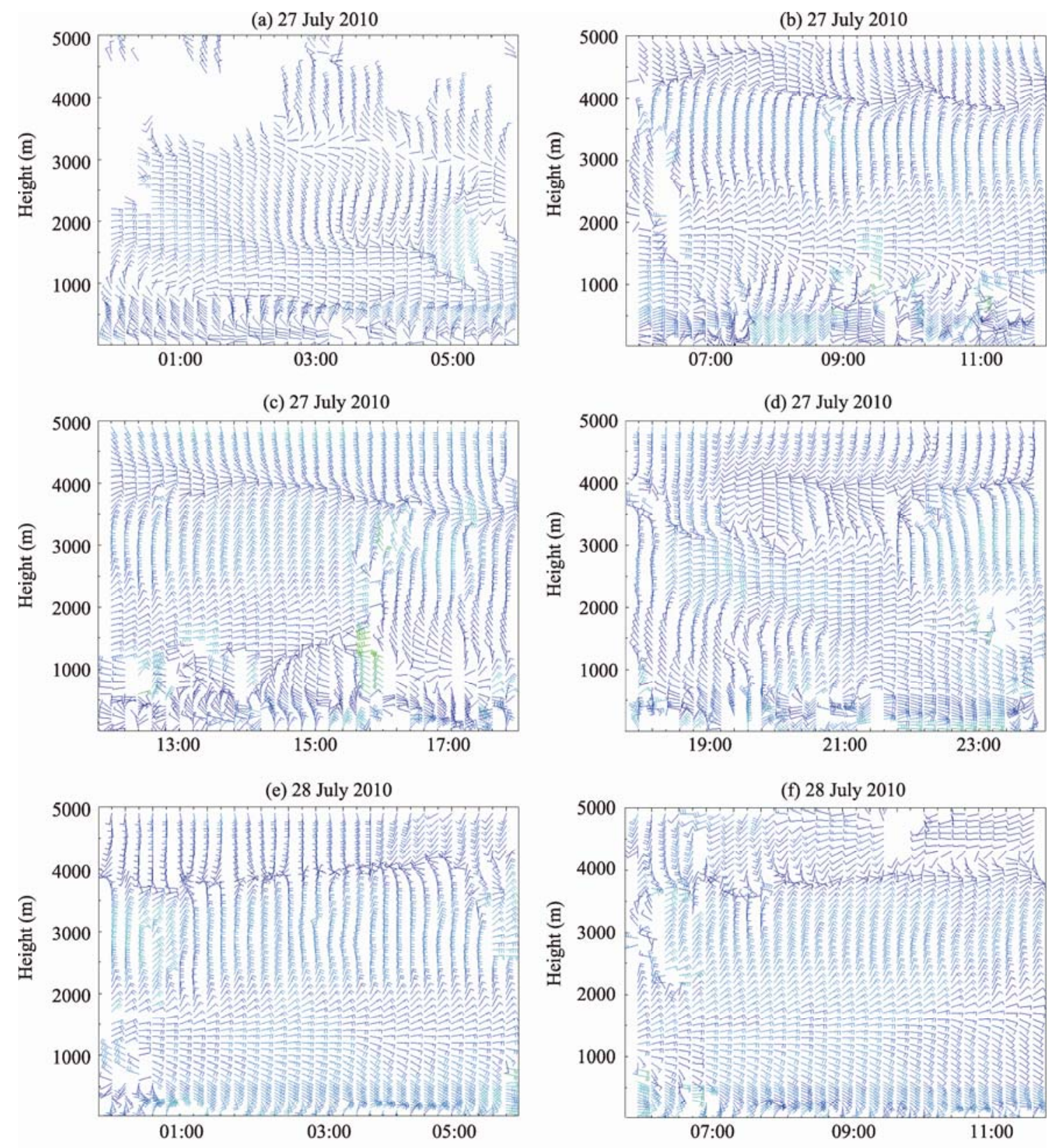

(g) 28 July 2010

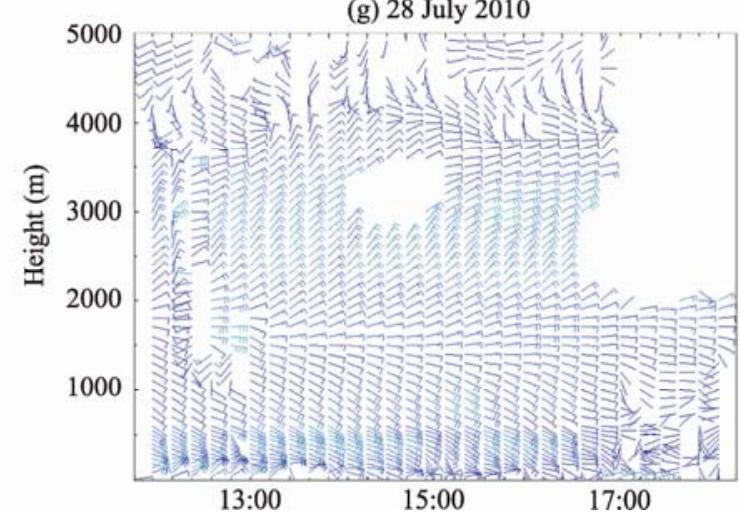

Fig. 3 Evolutions of horizontal wind speeds with time and height in 27-28 July 2010 
2.2.2 Wind profiler data for temperature advection retrieval

Since wind profiles have higher vertical spatial resolution, detailed structure of the temperature advection distribution with height can be calculated, and the variation trend in terms of hydrostatic stability in the atmosphere over a station can be further judged. According to the standard atmospheric features, the equation for calculating temperature advection from a single wind profiler is given by:

$$
-V \times \nabla T=-\frac{P f}{R_{d}} V \times\left(k \times \frac{\partial v}{\partial p}\right) .
$$

Where, $f$ is the Coriolis parameter; $R_{d}$ is the gas constant; and $k$ is the unit vector in the vertical direction. On the isobaric surface $P_{1}$ and $P_{2}\left(P_{1}>P_{2}\right)$, the wind velocities and directions are $\left(V_{1}, \theta_{1}\right)$ and $\left(V_{2}, \theta_{2}\right)$, respectively. Their expressing equations are as follows (Zhang et al., 2007):

$$
\begin{aligned}
& -V \times \nabla T \approx-\frac{\bar{p} f}{R_{d}}\left(\frac{V_{1}+V_{2}}{2}\right) \times\left(k \times \frac{V_{1}-V_{2}}{\Delta p}\right) \\
& =-\frac{\bar{p} f}{R_{d} \Delta p} \times k \times\left(V_{1} \times V_{2}\right) \\
& =-\frac{\bar{p} f}{R_{d} \Delta p} V_{1} V_{2} \sin \left(\theta_{1}-\theta_{2}\right) .
\end{aligned}
$$

Where, $\Delta p=p_{1}-p_{2}$, and $\bar{p}=\left(p_{1}+p_{2}\right) / 2$.

As the wind data observed from a wind profiling radar refer to the height in meter, a pressure-height conversion is needed. According to the known pressure-height relation, its correlation with temperature advection on the same coordinate as that of the wind profiles can be derived. Under standard atmospheric conditions, the correlation between the geopotential height and the atmospheric pressure is:

$$
Z=44331\left[1-\left(\frac{p}{1013.255}\right)^{0.1903}\right] .
$$

The correlation between the height and the geopotential height is:

$$
Z=\frac{9.80616(1-0.00259 \cos (2 \varphi))\left(1+\frac{h}{R_{0}}\right)^{2}}{9.80665} \times \frac{R_{0} h}{R_{0}+h} .
$$

Where, $R_{0}$ represents the Earth radius; $\varphi$ refers to the local latitude; $Z$ is the geopotential height; and $h$ is the elevation.

The nature and size of temperature advection can be determined from the wind direction changes with height according to the thermal wind principle. When the wind direction in a certain layer changes clockwise with height in the free atmosphere, it shows that warm advection exists in this layer; on the contrary, if the wind direction changes counterclockwise with height, cold advection must be in this layer (Zhu et al., 1984). As can be seen from Fig. 3, before the onset of precipitation (00:00-07:30 on 27 July), the winds below 2,500 $\mathrm{m}$ turned clockwise with height, indicating the atmosphere in this layer was affected by warm advection; after the onset of precipitation (07:30-16:00 on 27 July), the winds within $1,000-3,500 \mathrm{~m}$ turned counterclockwise with height, which suggests that cold advection was playing an important role in this layer. From 16:00 to 21:30, the wind direction changed again clockwise with height, showing the influence of warm advection in this layer once more. Figure 4 illustrates the temperature advection profiles that changed with time on 27 July 2010. Apparently, before it started to rain (00:00-07:30 on 27 July), the atmosphere below 2,500 m was mainly controlled by warm advection and in the period between 07:30 16:00 during the rainfall warm advection once again appeared in the atmosphere under $1,000 \mathrm{~m}$, with peak value getting to $30 \times 10^{-5} \mathrm{o} / \mathrm{s}$. However, during the same period cold advection existed in the atmospheric layer of 1,000-3,000 m and its maximum value was about $-31 \times 10^{-5}{ }^{\circ} \mathrm{C} / \mathrm{s}$. So, the atmosphere appeared in the form of "upper cold, lower warm", meaning the atmospheric structure was not stable, favorable for updraft motion and rainfall genesis. After 17:00, the atmosphere below $1,000 \mathrm{~m}$ was dominated by cold air advection with the maximum value of about $-30 \times 10^{-5}$ ${ }^{\circ} \mathrm{C} / \mathrm{s}$, while in the atmosphere above $1,000 \mathrm{~m}$ it was mainly warm advection, making the atmospheric layer get stable. The above analyses show that the temperature advections derived from wind profiler data can reproduce the true characteristics of low-level thermodynamics evolution in a precipitation process and that they can be used to judge the trend of hydrostatic stability variations. In the early stage of the rainfall process on 27 July, the low-level atmosphere was mainly controlled by warm advection, which had accumulated enough unstable energy to trigger the rainfall event, offering dynamic conditions for the updraft 
motion and vapor convergence. In the later stage of the precipitation, the lower atmosphere was affected by cold advection and the upper level by warm advection, making the atmosphere become stable and indicating the end of the rainfall process.

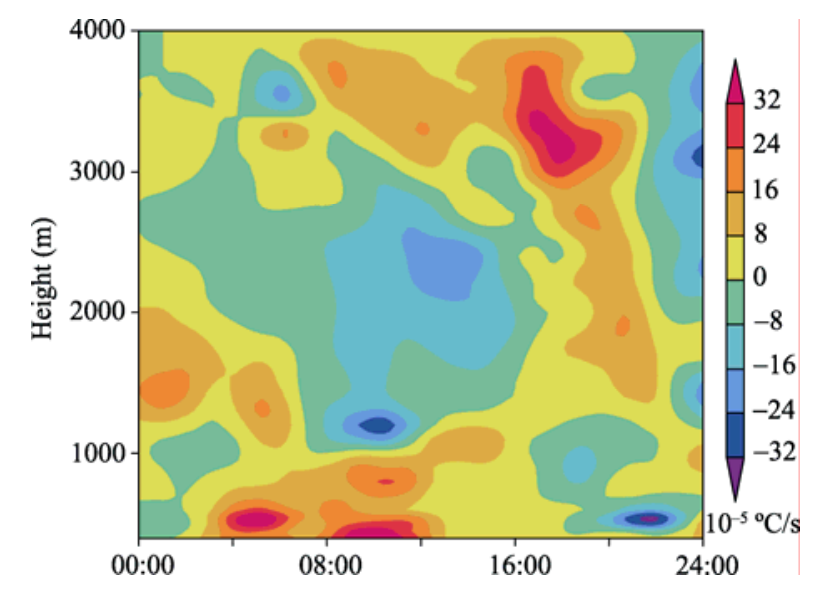

Fig. 4 Time and height of temperature advections during the rainfall on 27 July 2010

\subsubsection{Estimation of radar reflectivity factor $\mathrm{Z}$}

When wind profiling radar is used to detect rainfall, due to the fact that the ratio of the electromagnetic wavelength to the diameter of rain droplets is larger, rain droplets to the scattering of electromagnetic waves fit Rayleigh scattering more, and the common radar meteorological equation can be used to calculate the radar reflectivity factor $Z$, which is expressed as below (Ruan et al., 2002; Zhong et al., 2010):

$$
\begin{aligned}
Z= & \frac{1024 \times \ln 2 \times \lambda^{2} \times R^{2} \times L \times P_{r}}{\pi^{3} \times P_{t} \times h \times G^{2} \times \varphi \times \theta \times\left|\frac{m^{2}-1}{m^{2}+2}\right|^{2}}, \\
P_{r}= & S N R_{0} \times P_{n}, \\
P_{n} & =K \times T_{0} \times B \times N_{f} .
\end{aligned}
$$

Where, $S N R_{0}$ is original signal to noise ratio; $P_{n}$ is noise power; $K$ is Boltzmann constant $\left(K=1.38 \times 10^{-23}\right.$ $(J / K)) ; B$ is bandwidth of receiver; $T_{0}$ is absolute antenna temperature; $N_{f}$ is the noise coefficient; $\lambda$ is the electromagnetic wavelength; $R$ defines the distance to a target; $L$ is antenna feeder power loss; $P_{r}$ is echo power; $\pi$ is a constant; $P_{t}$ is transmitting peak power; $G$ is antenna gain; $\varphi, \theta$ are horizontal and vertical beam width, respectively; $\left|\frac{m^{2}-1}{m^{2}+2}\right|^{2}$ is a dielectric constant (0.93); and $Z$ is reflectivity factor (echo intensity).

In the course of calculation, the noise power of receiver $P_{n}$ is obtained first, and the original signal to noise ratio $S N R_{0}$ is derived without coherent accumulation in order to give true echo signals, then the echo power $P_{r}$ is calculated, and finally the radar reflectivity factor $Z$ (echo intensity) is derived.

Figure 5 gives the time and height profile of reflectivity factor $\mathrm{Z}$ of the wind profiling radar (WPR) during the rainfall event on 27 July. It is clearly seen that the onset time of the rain is correspondent well to the variation of large $Z$ value zone. The rains mainly fell in the periods of $07: 33-08: 48,09: 56-10: 33$, $12: 11-12: 40,14: 08-14: 27,15: 12-15: 25,15: 45-16: 13$, 16:39-17:09, 18:04-20:05, 20:40-20:57, 21:16-22:27, and 22:46- 22:55. As it rained, the processes just matched the red and yellow zones in the figure, i.e. the large $Z$. The reflectivity factor $Z$ varied in the range of 18-38 dBZ, which indicates that when the rain events occurred, the rain droplet particle backscatter to electromagnetic waves was enhanced, increasing the reflectivity factor $Z$, but before the rainfall the backscatter intensity of atmosphere to electromagnetic waves was relatively weak, with a smaller value of $Z$. Therefore, there was a very good correlation between the onset time of precipitation and the large value of $Z$. In addition, by analyzing the reflectivity factor $Z$, it can be judged initially that the rain droplets in the process of the rainfall formed at the height of 3,800-4,500 m. These results imply that during the processes of rainfall events, what radar reflectivity factor $\mathrm{Z}$ mainly reflects is the backscatter intensity of rain cloud particles to electromagnetic waves, which matches well with

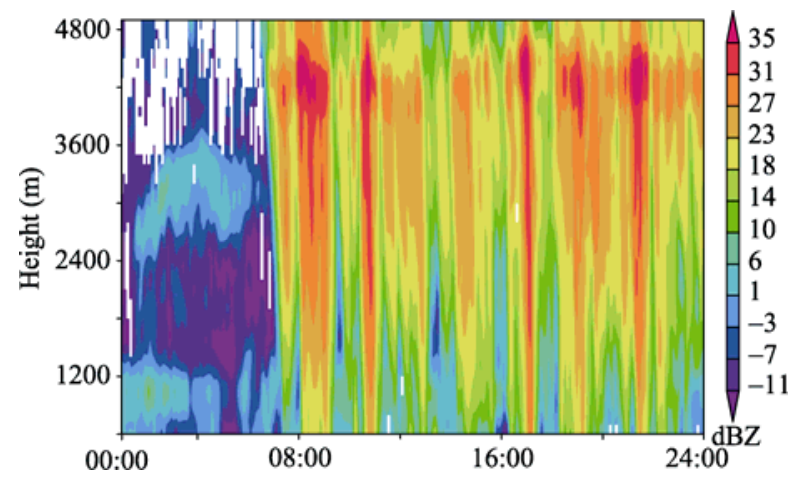

Fig. 5 Time and height profiles of radar reflectivity factor $Z$ during the rainfall process on 27 July 2010 
the height for the formation of rain cloud particles, the duration of the precipitation and the precipitation intensity.

\section{Conclusions}

Using the wind profiler data obtained during the rainfall process on 27 July, this paper studied the dynamics, thermodynamics, and intensity of the rainfall in order to apply the high temporal and spatial resolution WPR data to weather analyses and forecasts for the Tarim Oilfield region in the future. Some initial conclusions can be drawn as follows:

(1) Although wind profiling radar (WPR) only provides the data of vertical wind speeds and directions on a local scale, which have very high temporal resolution and high vertical spatial resolution, it can be used to analyze detailed vertical structures of the atmosphere and the characteristics of a meso-scale system during rainfall processes. Before and after the rainfall event on 27 July, the wind fields presented multi-layer structures vertically with one obvious meso-scale shear line and three airflows from different directions, which accelerated the motion of updraft convergence in the lower atmosphere. Before and after the rainfall, the winds blew inversely with height. Before the rain, wind directions turned clockwise, but after the onset of the rainfall, the wind directions

\section{References}

Angevine W M. 1997. Errors in mean vertical velocities measured by boundary layer wind profilers. Journal of Atmospheric and Oceanic Technology, 14: 565-569.

Balsley B B, Ecklund W L, Carter D A, et al. 1988. Average vertical motions in the tropical atmosphere observed by a wind profiler on Pohnpei ( $7^{\circ} \mathrm{N}$ Latitude, $157^{\circ} \mathrm{E}$ Longitude). Journal of Atmospheric Science, 45(3): 396-405.

Chilson P B, Ulbrich C W, Larsen M F, et al. 1993. Observations of a tropical thunderstorm using a vertically pointing dual-frequency collinear beam Doppler radar. Journal of Atmospheric and Oceanic Technology, 10: 663-673.

Currier P E, Avery S K, Balsley B B, et al. 1992. Use of two wind profilers in the estimation of raindrop size distribution. Geophysical Research Letters, 19: 1017-1020.

Deshpande S M, Raj P E. 2009. UHF wind profiler observations during a tropical pre-monsoon thunderstorm-A case study. Atmospheric Research, 93: 179-187.

Ecklund W L, Gage K S, Williams C R. 1995. Tropical precipitation changed counterclockwise with height.

(2) The temperature advection derived from wind profiler data can reproduce the characteristics of low-level thermodynamic evolution in the process of rainfall, being able to show the trend of hydrostatic stability variations of the atmosphere. In the early stage of the rainfall process on 27 July, the low-level atmosphere was mainly controlled by warm advection, which had accumulated enough unstable energy to trigger the rainfall event, and was favorable for the updraft motion of the atmosphere and the occurrence of precipitation.

(3) The large value zone of radar reflectivity factor $\mathrm{Z}$ has better corresponding correlations with the onset and end of precipitation, the height for the formation of rain cloud particles, and the precipitation intensity. The reflectivity factor $\mathrm{Z}$ during the process of this rainfall ranged from 18 to $38 \mathrm{dBZ}$, and the rain droplets formed mainly at the level of 3,800-4,500 m.

\section{Acknowledgements}

This research was co-funded by the National Basic Research Program of China (2010CB951001), the Research Subject with the Support of National Science and Technology (2012BA C23B01), and the Central Scientific Research and Operational Project (IDM201002). The authors thank Mr. KeMing ZHAO and Ms. He QIN, two meteorological engineers from the Xinjiang Meteorological Observatory for their valuable assistance.

studies using a 915-MHz wind profiler. Radio Science, 30: 1055-1064. Fukao S, Wakasugi K, Sato T, et al. 1985. Direct measurement of air and precipitation particle motion by very high frequency Doppler radar. Nature, 316: 712-714.

Gage K S, Williams C R, Ecklund W L. 1996. Application of the 915 $\mathrm{MHz}$ profiler for diagnosing and classifying tropical precipitating cloud systems. Meteorology and Atmospheric Physics, 59: 141-151.

Gu Y X, Tao Z Y. 1993. Analysis and Application of UHF Wind Profiler Radar Data during 1989-1990. MesoScale Meteorology Corpus. Beijing: China Meteorology Press, 194-201.

He P. 2006. Phased Array Wind Profiler Radar. Beijing: China Meteorological Press, 2-3.

He P, Zhu X Y, Ruan Z, et al. 2009. Preliminary study on precipitation process detection using wind profiler radar. Journal of Applied Meteorological Science, 20(4): 465-470.

Kuo Y-H, Donall E G, Shapiro M A. 1987. Feasibility of short-range numerical weather prediction using observations from a network of profilers. Monthly Weather Review, 115: 2402-2427. 
Maguire W B, Avery S K. 1994. Retrieval of raindrop size distributions using two Doppler wind profilers: model sensitivity testing. Journal of Applied Meteorology, 33: 1623-1635.

Rao T N, Rao D N, Raghavan S. 1999. Tropical precipitating systems observed with Indian MST radar. Radio Science, 34: 1125-1139.

Ruan Z, Ge R S, Wu Z G. 2002. The reach of a method for the rain cloud structure with wind profiler. Journal of Applied Meteorological Science, 13(3): 170-179.

Wakasugi K, Mizutani A, Matsuo M. 1986. A direct method for deriving drop-size distribution and vertical air velocities from VHF Doppler radar spectra. Journal of Atmospheric and Oceanic Technology, 3: 623-629.

Xin T E, He Q S, Wei H R, et al. 2009. Observation and study of wind velocity variation with altitude over the EXPO land, Shanghai. Plateau Meteorology, 28(1): 127-135.

Zhang G C, Jiao M Y, Li Y X. 2007. Techniques and Methods of Contemporary Weather Forecast. Beijing: China Meteorological Press, 78-99.

Zhong L J, Ruan Z, Ge R S, et al. 2010. Calibration method of echo intensity of wind profile radar. Journal of Applied Meteorological Science, 21(5): 598-605.

Zhu Q G, Lin J R, Shou S W. 1984. Synoptic Meteorology Theory and Method. Beijing: China Meteorological Press, 444-446.

Zou H, Li P, Zhu J H, et al. 2007. Observational study on the wind from wind-profiler during HEST2007. Plateau Meteorology, 26(6): 1199-1207. 